\title{
X-ray analysis of foramen rotundum for preliminary diagnosis of fossa pterygopalatina lesions
}

\author{
Selma Çalışkan ${ }^{1}$, Emre Can Çelebioğlu' ${ }^{2}$, Sinem Akkaşoğlu ${ }^{1}$, Mustafa Fevzi Sargon ${ }^{3}$ \\ ${ }^{1}$ Department of Anatomy, School of Medicine, Ankara Yildrrm Beyazıt University, Ankara, Turkey \\ ${ }^{2}$ Department of Radiology, School of Medicine, TOBB University, Ankara, Turkey \\ ${ }^{3}$ Department of Anatomy, School of Medicine, Hacettepe University, Ankara, Turkey
}

\begin{abstract}
Objectives: Fossa pterygopalatina is located posterior to maxillary sinus, anterior to pterygoid plates and inferior to greater sphenoid wing. Tumors that arise in fossa pterygopalatina are usually asymptomatic and often discovered at late stage. Because of its deep and relative inaccessible location, clinical examination of fossa pterygopalatina is difficult. Aplastic or nonvisible foramen rotundum may give an early indication for the regional tumors.

Methods: In the present study, foramen rotundum was visualized as a round structure with prominent sclerotic margins located near ethmoid cells, maxillary sinus or orbital cavity in X ray images. X-rays (radiographs) of 17 dry skulls and 7 half dry skulls were performed with Phillips Digital Diagnost X-Ray device. All dry skulls were positioned similar to Caldwell's view. We have designed a fixation apparatus to optimize the positioning of dry skulls and half skulls. After fixation of the skulls with the apparatus, the X-ray beam centered about 3-4 cm below the external occipital protuberance with an angle of 15 degrees to the chantomeatal line. Each radiologic image was examined for the location of foramen rotundum in relation with orbital cavity, ethmoidal cells and maxillary sinuses. We described the characteristic of foramen rotundum with count and percent values.

Results: In the present study, 41 foramina rotunda were analyzed. Out of 41 foramina rotunda, twenty were right-sided, twenty one were left-sided. Of the 20 right-sided foramina rotunda, 19 were visible on X-ray images. On the other side 18 of 21 leftsided foramina rotunda were apparent. 14 of 19 visible right-sided foramina rotunda were identified in the orbital cavity (73.68\%). Three of them were identified in ethmoidal cells, and two in the maxillary sinus. 11 of 18 visible left-sided foramina rotunda were identified in the orbital cavity (61.11\%). Two of these were found in ethmoidal cells, eight in the maxillary sinus. Out of 17 dry skulls, one had bilateral nonvisible foramina rotunda.
\end{abstract}

Conclusion: Foramen rotundum must be taken into consideration in evaluation of routine X-rays to prevent misdiagnosis of the patients with persistent non-specific symptoms.

Keywords: cranium; foramen rotundum; pterygopalatine fossa; X-ray

Anatomy 2018;12(2):61-64 @ 2018 Turkish Society of Anatomy and Clinical Anatomy (TSACA)

\section{Introduction}

Fossa pterygopalatina is located posterior to maxillary sinus, anterior to pterygoid plates and inferior to greater sphenoid wing. ${ }^{[1]}$ It has connections with infratemporal fossa via the pterygomaxillary fissure, nasal cavity via the sphenopalatine foramen, orbit via the inferior orbital fissure, oral cavity via the palatine foramina and middle cranial fossa via the foramen rotundum. ${ }^{[1,2]}$ Maxillary nerve, maxillary artery and pterygopalatine ganglion are contents of fossa pterygopalatina. ${ }^{[3]}$ Maxillary nerve originates at the Gasserian ganglion, passes via the foramen rotundum to exit the cranium, crosses fossa pterygopalatina and enters the infraorbital canal. ${ }^{[2]}$ Fossa pterygopalatina tumors are usually asymptomatic and often discovered at late stage. ${ }^{[3]}$ Clinical examination of fossa pterygopalatina is difficult due to its deep and relative inaccessible location. ${ }^{[4]}$

Orbital pseudotumors extending into fossa pterygopalatina have been reported. ${ }^{[5]}$ Lesions originating in oral 
and maxillofacial regions and tumors from the sinonasal region may also extend to the pteryogopalatine fossa. ${ }^{[3]}$ These sinonasal region tumors may be overlooked by patients and physicians because of their non-specific symptoms. ${ }^{[3]}$ Some of the non-specific symptoms reported in the literature related to the pathologies of fossa pterygopalatina are nasal obstruction, headache, infraorbital pain, facial numbness, nausea and vomiting, hyposmia, rhinorrhea, hearing impairment, diplopia, exophthalmos and epiphora. ${ }^{[6]}$ Foramen rotundum may be absent in a rare neurocutaneous disorder named Gómez-López-Hernández syndrome characterized by rhombencephalosynapsis, parietooccipital alopecia, brachycephaly, facial malformations, trigeminal anesthesia. ${ }^{[7]}$ Thus, aplastic or nonvisible foramen rotundum may give an early indication for aforementioned diseases. In the present study, foramen rotundum was visualized as a round structure with prominent sclerotic margins located near ethmoid cells, maxillary sinus or orbital cavity in X-ray images.

\section{Materials and Methods}

Study data were collected from Departments of Anatomy of Ankara Yıldırım Beyazıt University and Hacettepe University. 17 craniums and 7 half craniums were evaluated. X-rays (radiographs) of 17 dry skulls and 7 half dry skulls were taken at TOBB ETU University using Phillips Digital Diagnost C50 X-ray device (Philips Medical Systems, Hamburg, Germany). All dry skulls were positioned to Caldwell's viewwith the forehead and nose placed against $\mathrm{X}$-ray detector. This projection is one of the most commonly used cranial $\mathrm{X}$-ray projections for visualization of the paranasal sinuses, especially the frontal sinuses. We positioned the skulls and half skulls as shown in Figure 1. The $X$-ray beam was centered about $3-4 \mathrm{~cm}$ below the external occipital protuberance with an angle of $15^{\circ}$ to the canthomeatal line.

\section{Results}

Each radiologic image was examined for the location of foramen rotundum in relation to the orbital cavity, ethmoidal cells and maxillary sinuses. We described the characteristics of foramen rotunda with count and percent values. In the present study, 41 foramina rotunda (20 on the right side and 21 on the left side) were examined. Of the 20 right-sided foramina rotunda, 19 were visible on X-ray images. On the other side, 18 of 21 left-sided foramina rotunda were apparent.

14 of the 19 visible right-sided foramina rotunda were identified in the orbital cavity (73.68\%) (Figure 2), while three were identified within the ethmoidal cells, and two in the maxillary sinus (Figure 3). 11 of 18 visible left-sided

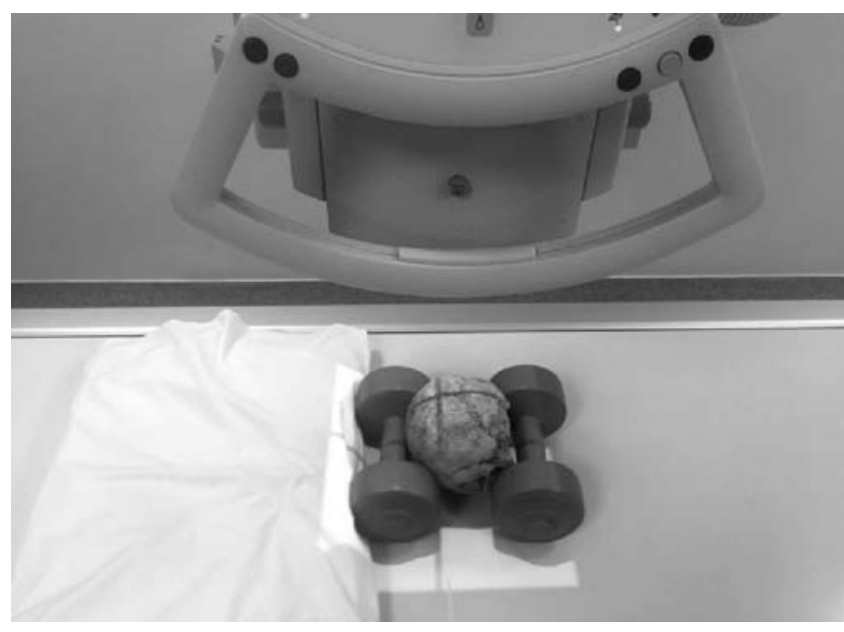

Figure 1. Cranium positioned similar to Caldwell's view against $X$-ray detector.

foramina rotunda were identified in the orbital cavity $(61.11 \%)$ (Figure 2$)$, two were within ethmoidal cells (Figure 4), and 8 in the maxillary sinus (Figure 3). Out of 17 dry skulls, one had bilateral nonvisible foramina rotunda (Figure 5).

\section{Discussion}

Most of the patients with non-specific symptoms (i. e. nasal obstruction, headache, infraorbital pain, facial numbness, nausea and vomiting, hyposmia, rhinorrhea, hearing impairment, diplopia, exophthalmos and epipho-

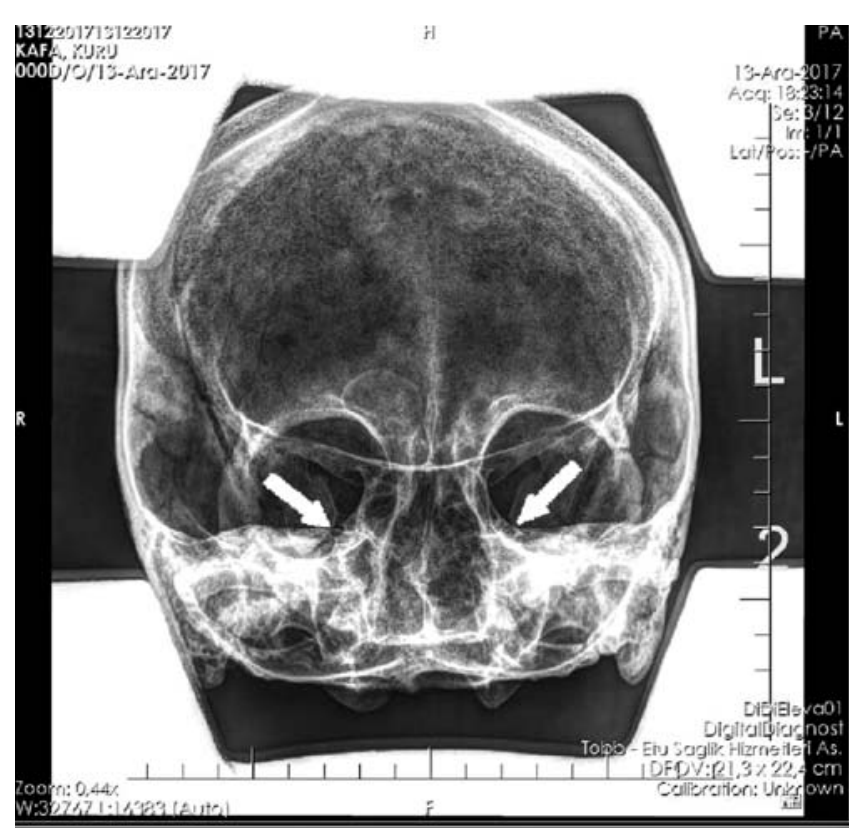

Figure 2. Bilateral foramina rotunda in orbital cavities on X-ray. 


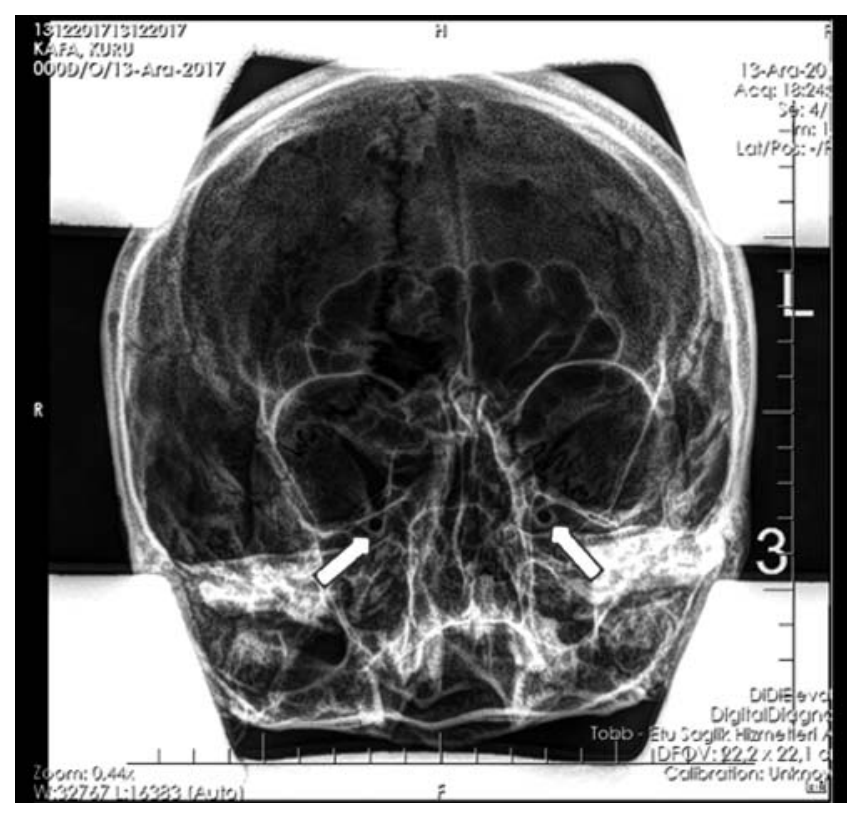

Figure 3. Bilateral foramina rotunda in maxillary sinuses on X-ray.

ra) undergo $\mathrm{X}$-ray visualization as a first order examination in family medicine centers. Foramen rotundum is a structure which is not generally taken into consideration during routine $\mathrm{X}$-ray image evaluation. This anatomic structure is located at a key point at skull base. ${ }^{[1,2]}$ It is important to realize foramen rotundum on routine $\mathrm{X}$-rays to diagnose and distinguish pathologies developed near this structure from normal findings. We suggest that tumors which arise in fossa pterygopalatina and tumors which extend to fossa pterygopalatina from oral, orbital and maxillofacial regions may obscure radiologic visualization of this key structure.

Thus, there is need for comparative studies for radiologic evaluation of foramen rotundum between patients with normal findings and with patients who have fossa pterygopalatina pathologies. X-ray evaluation of foramen rotundum in large series of patients with no evidence of disease that might alter foraminal anatomy should be base for the following studies. Besides tumors detection of aplastic foramina rotunda may give an early indication of Gómez-López-Hernández syndrome; a rare neurocutaneous disorder which is characterized by rhombencephalosynapsis, parieto-occipital alopecia, and trigeminal anesthesia. ${ }^{[7]}$

There are studies in the literature, performed on both dry skulls and CT (computed tomography) scans. Liu et al. ${ }^{[8]}$ studied the size of foramen rotundum of 51 patients with computed tomography (CT) to indicate the etiology of trigeminal neuralgia. Berlis et al. ${ }^{[9]}$ analyzed the size of

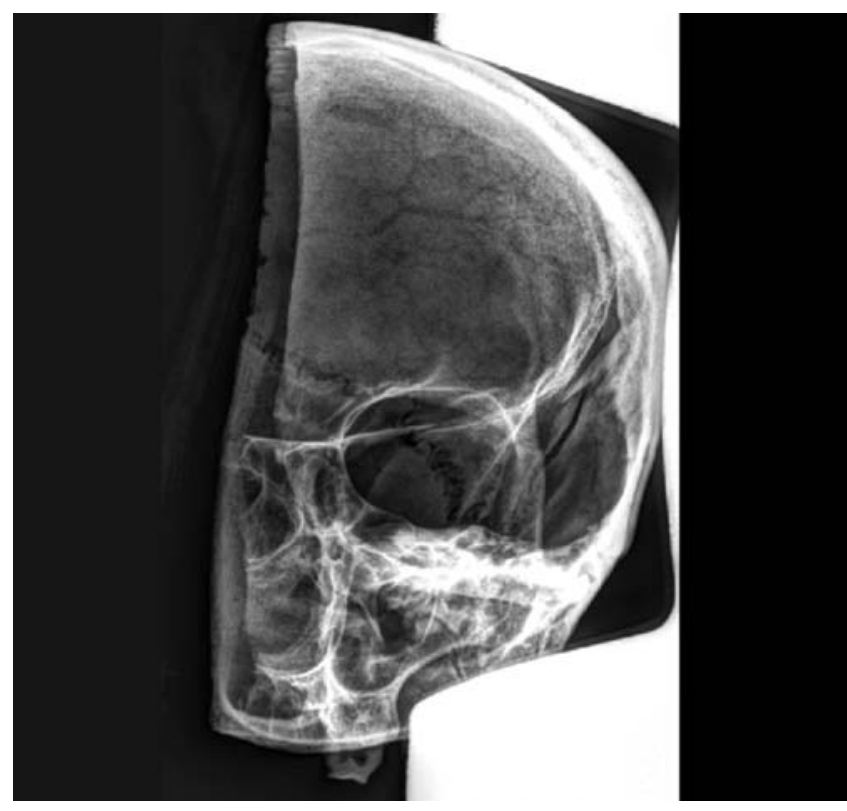

Figure 4. Unilateral foramen rotundum in ethmoidal cells on X-ray.

foramen rotundum on 60 dry skulls using CT and measured the average diameters as $3.9 \times 3.13 \mathrm{~mm}$. Edwards et $\mathrm{al}^{[10]}$ reviewed the size of foramen rotundum and claimed that a narrow foramen due to achondroplasia, fibrous dysplasia, osteopetrosis, malignant schwannoma may present severe clinical consequences. Hedeman et al. ${ }^{[11]}$ reported two cases with schwannoma of Gasserian ganglion protruding into foramen rotundum and causing

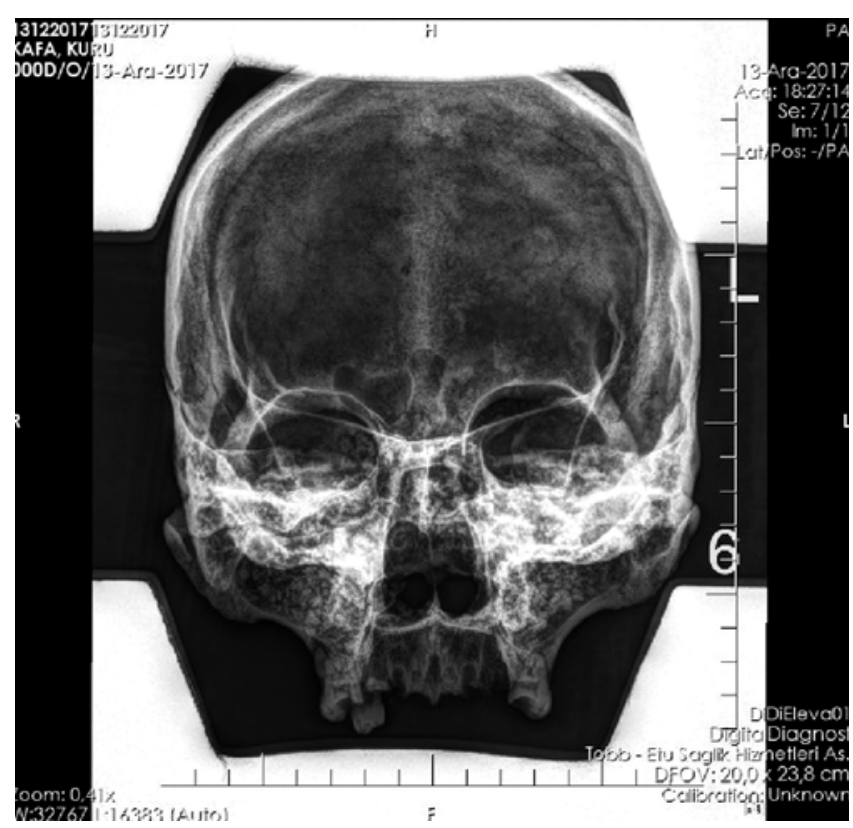

Figure 5. Nonvisible foramen rotundum. 
right-sided pain and a burning sensation along the maxillary nerve.

Although CT is valuable to measure the size of the foramen rotundum, it is not a routine imaging technique. Indications of the patients undergoing CT imaging must be well-defined. Foramen rotundum can be visualized with cheap and easily performed X-ray imaging to reveal soft tissue masses obscuring foramen rotundum.

\section{Conclusion}

Foramen rotundum must be taken into consideration in evaluation of routine $\mathrm{X}$-rays to prevent misdiagnosis of the patients with persistent non-specific symptoms mentioned above.Therefore, radiologists should be familiar with the X-ray view of this important structure and attaching this key structure to the reporting templates will make a difference.

\section{References}

1. DelGaudio JM. Endoscopic transnasal approach to the pterygopalatine fossa. Arch Otolaryngol Head Neck Surg2003;129:441-6.

2. Xue T, Yang W, Guo Y, Yuan W, Dai J, Zhao Z. 3D image-guided percutaneous radiofrequency thermocoagulation of the maxillary branch of the trigeminal nerve through foramen rotundum for the treatment of trigeminal neuralgia. Medicine (Baltimore) 2015;94: e1954.
3. Ordones AB, Fornazieri MA, PinnaFde R, Bezerra TF, Voegels RL, Sennes LU. Transpterygoid approach to a dermoid cyst in pterygopalatine fossa. Int Arch Otorhinolaryngol 2014;18:83-6.

4. Cheng Y, Xu H, Chen Y, Xu S, Yu H, Zhang S, Feng Y, Zhao G. Location of pterygopalatine fossa and its relationships to the structures in sellar region. J Craniofac Surg 2015;1049-2275

5. Lee EJ, Jung SL, Kim BS, Ahn KJ, Kim YJ, Jung AK, Park CS, Song SY, Park NH, Kim MS. MR imaging of orbital inflammatory pseudotumors with extraorbital extension. Korean J Radiol 2005; 6:82-8.

6. Zhou H, Xing G, Gao X, Wang J, Chen F, Lu L, Zhang Y, Chen Z, Qian X. Schwannomaof the sinonasal tract and the pterygopalatine fossa with or without intracranial extension. ORL J Otorhinolaryngol Relat Spec 2015;77:61-9.

7. Choudhri AF, Patel RM, Wilroy RS, Pivnick EK, Whitehead MT. Trigeminal nerve agenesis with absence of foramina rotunda in Gómez-López-Hernández syndrome. Am J Med Genet A 167A: 238-42.

8. Liu P, Zhong W, Liao C, Liu M, Zhang W. Narrow foramen ovale and rotundum: a role in the etiology of trigeminal neuralgia. $\mathrm{J}$ Craniofac Surg 2016;27:2168-70.

9. Berlis A, Putz R, Schumacher M. Direct and CT measurements of canals and foramina of the skull base. Br J Radiol 1992;65:653-61.

10. Edwards B, Wang JM, Iwanaga J, Loukas M, Tubbs RS. Cranial nerve foramina part I: a review of the anatomy and pathology of cranial nerve foramina of the anterior and middle fossa. Cureus 2018;10: e2172.

11. Hedeman LS, Lewinsky BS, Kochridge GK, Trevor R. Primary malignant schwannoma of the Gasserian ganglion. J Neurosurg 1978; 48:279-83.

\author{
Correspondence to: Sinem Akkaşoğlu \\ Department of Anatomy, School of Medicine, \\ Ankara Yıldırım Beyazıt University, Ankara, Turkey \\ Phone: +90 $3123241555 / 4637$ \\ e-mail: snm222@hotmail.com
}

deomed. Conflict of interest statement: No conflicts declared.

This is an open access article distributed under the terms of the Creative Commons Attribution-NonCommercial-NoDerivs 3.0 Unported (CC BY-NCND3.0) Licence (http://creativecommons.org/licenses/by-nc-nd/3.0/) which permits unrestricted noncommercial use, distribution, and reproduction in any medium, provided the original work is properly cited. Please cite this article as: Çalışkan S, Çelebioğlu EC, Akkaşoğlu S, Sargon MF. X-ray analysis of foramen rotundum for preliminary diagnosis of fossa pterygopalatinalesions. Anatomy 2018;12(2):61-64. 